Contract No. and Disclaimer:

This manuscript has been authored by Savannah River Nuclear Solutions, LLC under Contract No. DE-AC09-08SR22470 with the U.S. Department of Energy. The United States Government retains and the publisher, by accepting this article for publication, acknowledges that the United States Government retains a non-exclusive, paid-up, irrevocable, worldwide license to publish or reproduce the published form of this work, or allow others to do so, for United States Government purposes. 


\title{
SHARING AND DEPLOYING INNOVATIVE INFORMATION TECHNOLOGY SOLUTIONS \\ TO MANAGE WASTE ACROSS THE DOE COMPLEX - 11309
}

\author{
Regina Crolley*, Michael Thompson*, Terry Wentz**, Dean Newton*** \\ *Savannah River Site, Aiken, SC 29808 \\ ** Mission Support Alliance, Hanford, WA 99352 \\ ***Turnkey Transportation Services, Oak Ridge, TN 37831
}

\begin{abstract}
Collaboration between US Department of Energy (DOE) complex sites is improving time to delivery and cost efficiencies for waste management missions with new information technologies (IT) such as wireless computing, global positioning satellite (GPS), and radio frequency identification (RFID). Integrated solutions developed at separate DOE complex sites by new technology Centers of Excellence (CoE) have increased material control and accountability, worker safety, and environmental sustainability. CoEs offer other DOE sister sites significant cost and time savings by leveraging their technology expertise in project scoping, implementation, and ongoing operations.
\end{abstract}

\section{INTRODUCTION}

There has been a need for a faster and cheaper deployment model for information technology (IT) solutions to address waste management needs at US Department of Energy (DOE) complex sites for years. Budget constraints, challenges in deploying new technologies, frequent travel, and increased job demands for existing employees have prevented IT organizations from staying abreast of new technologies or deploying them quickly.

Despite such challenges, IT organizations have added significant value to waste management handling through better worker safety, tracking, characterization, and disposition at DOE complex sites. Systems developed for site-specific missions have broad applicability to waste management challenges and in many cases have been expanded to meet other waste missions. Radio frequency identification (RFID) and global positioning satellite (GPS)-enabled solutions have reduced the risk of radiation exposure and safety risks. New web-based and mobile applications have enabled precision characterization and control of nuclear materials. These solutions have also improved 
operational efficiencies and shortened schedules, reduced cost, and improved regulatory compliance.

IT and mission management at DOE sites Hanford, Oak Ridge and Savannah River have collaborated on these solutions because of common self-interest in the face of limited resources to share IT solutions. The result has been a growing collaboration and interdependency model based on the technology center of excellence (CoE) concept that promotes specialization and interdependence. The DOE-Environmental Management Chief Information Officer (CIO) recognized the need to institutionalize collaboration and has championed CoE solutions for more standardized, cost effective technologies to support the waste management cycle. CoEs provide mission and IT managers the ability to apply the latest IT solutions at a fraction of the time and cost of developing solutions independently.

\section{INNOVATION THROUGH COLLABORATION AND SHARING}

A center of excellence "is a premier organization providing an exceptional product or service in an assigned sphere of expertise and within a specific field of technology, business, or government, consistent with the unique requirements and capabilities of the COE organization”. (1) The context for CoEs within DOE is the more than 20 national laboratories and technology centers and 20 operations offices complex sites. (2)

Capabilities and expertise in next generation technologies such as wireless and mobile application development are not widespread. The Hanford, Oak Ridge, and Savannah River complex sites have overcome their individual resource constraints to rapidly develop and deploy common integrated solutions for their waste management problems. Using solution blueprinting, they have collaborated to leverage technology research, pilot projects, experiences, and best practices to apply parts or all of the solutions to waste management problems at other sites. Their solutions integrate multiple technologies such as RFID, wireless, web applications, GPS, and hand-held computing to solve waste management problems.

The collaboration model, based on information exchange and joint problem solving, has matured as it has demonstrated successes to participants and been endorsed by the DOE CIO. CoEs have emerged as they demonstrated their leadership in technology application to waste management problems. 
Fig.1. Collaboration Model for Solutions Sharing

1) Solutions Sharing: Managers provide summaries of their current project pipeline and discuss business requests for new technology applications at collaboration meetings across DOE and monthly IT governance calls

2) Establish Contact for Evaluation: Based on potential solutions, managers establish contact with technical solution owner for a DOE and/or site sponsored visits and evaluation.

3) Share Results: Technical solution owner shares white papers, DOE-approved security baselines, and other project archive materials in face-to-face interviews.

4) Share Solution Capital: Depending on need, management and technical solution owner share proprietary or source code under the direction DOE. In some cases, DOE complex sites may deploy a shared services model where one DOE location provides hosting and support for other locations. In other cases, the DOE site may provide general implementation support from subject matter experts.

\section{CoE: WIRELESS TECHNOLOGY DOE SITE: HANFORD}

In the first year of the Mission Support Alliance LLC (MSA) contract, two customers, CH2M HILL Plateau Remediation Company (CHPRC) and Washington River Protection Solutions (WRPS), added 1,550 and 1,275 employees respectively (3). These new employees would be performing cleanup work in 100, 200, and 600 Areas across the Hanford Site. To efficiently and effectively perform this work safely, the job sites need access to Hanford voice and network systems immediately.

Installation of traditional fiber optic and copper cables to deliver the needed information management (IM) services could not be accomplished in time and was cost prohibitive. Instead, an innovative approach using Worldwide Interoperability for Microwave Access (WiMAX) and Voice over Internet Protocol (VoIP) systems was implemented to provide wireless coverage and integrate voice and data services to the remote locations. The 
WiMAX system implemented covers approximately 360 square miles of the 586-squaremile Hanford Site. As a result, projects were able to get the IM services they needed, where they needed them, in a timely fashion, and at a cost of about \$2 million less than traditional fiber and copper solutions.(4)

Hanford's expertise in wireless technologies directly benefited Savannah River in 2010 when IT management deployed a WiMAX link to the R-area. The new link provided remote workers wireless access so they would not have to drive several miles a day and manually enter data into site applications. Hanford provided field testing support for Savannah River and security assessments which accelerated the project testing and implementation schedules.

\section{CoE: RFID}

\section{DOE SITE: OAK RIDGE}

Cleanup activities at the Oak Ridge Reservation address environmental legacies from nuclear weapons production and nuclear energy research. Cleanup includes environmental remediation, decontamination and decommissioning (D\&D) of radioactively-contaminated facilities, and disposition of the radioactive waste.

The K-25 Project is estimated to generate over 229,366 cubic meters of waste, roughly 30,000 truckloads -for packaging, transportation and disposal. The Bechtel Jacobs Company ships another 1.59 to 1.81 million kilograms of waste a day to the Environmental Management Waste Management Facility (EMWMF) at the Oak Ridge Complex. (5)

Management needed to identify opportunities for optimization of the transportation and disposal process, ensuring that the EMWMF could efficiently accommodate 240 trucks a day during peak periods. There was also a need to improve continuous daytime operations so that vehicle flow and communication/harmonization between projects could be maintained.

The Radio Frequency Identification Transport System (RFITS) was developed to minimize the cycle time for the disposition of waste from the K-25 Project to and from the waste disposal site, implement a paperless shipping process using RFID technology to reduce or eliminate the paperwork, and comply with environmental sustainability programs.

The RFITS system includes RFID vehicle tags that capture real time shipping data from the vehicle. Tags are interrogated by RFID readers and data is sent to RFITS as the 
vehicle enters its route. Activity can then be monitored by different organizations such as D\&D Projects, Transportation Operations, Physical Security and EMWMF operations.

RFITS has eliminated manual paperwork from the waste shipment process, resulting in less truck idle time (waste of waiting in line with the engine running). This decrease in truck run time positively supports the site's sustainable development goals.

Approximately 227,125 liters of fuel will be saved by the contractor, $\mathrm{NO}_{\mathrm{x}}$ emissions are reduced by 2,955 kilograms, and $\mathrm{CO}_{2}$ emissions are reduced by 159,091 kilograms. (5)

Using this automated process, approximately 45 kilograms of air pollution and 1.81 metric tons of paper are avoided, saving 40 trees, 47,318 liters of water, and 7,500 KWH of electricity that would have been used in paper production processes. These environmental savings were based on original projections of 30,000 shipments.

The Six Sigma Process Improvement Project (PIP) estimated the savings to the K-25 project to be $\$ 7.6 \mathrm{M}$ in cost avoidance. (5)

While this RFID based system was developed for a specific waste management problem, it will serve as a model for the DOE sites to focus complex-wide standards regarding onsite electronic shipping and transportation of hazardous or contaminated waste. Oak Ridge technical solution owners demonstrated the solution in April 2010 to leadership at Savannah River and shared solution specifications for potential implementation.

As DOE accelerates the completion of soil \& groundwater remediation and facility deactivation at the larger sites, multiple generation sites with accelerated schedules will inevitably be shipping to the same disposal facilities and can leverage the RIFITS system. Incorporating RFID technology will provide additional efficiencies for other DOE facilities where equipment or non-waste materials must be monitored and tracked with supporting documentation on all tracked items.

\section{CoE: Application development and hosting DOE SITE: Savannah River}

The Local Area Nuclear Material Accountability Software (LANMAS) application was developed in the 1990s to replace aging material control and accountability (MC\&A) software throughout the DOE complex. The software supports core material accounting and material control functions of a comprehensive safeguards systems in an operating nuclear facility. It is provided to all contractors and satisfies essential records and reporting requirements for the control and accountability of nuclear materials. 
As a material is received onto a site or created at a site, its entire lifecycle can be tracked in LANMAS complete to its termination of safeguards. LANMAS maintains information about the location, physical/chemical form, status, and quantity of individual nuclear materials. It also contains information about containers, tamper indicating devices (TIDs), and foreign obligations.

LANMAS is supported by a development team of three IT developers at Savannah River. It is designed with an open architecture that allows for site specific plug-ins/bolt-ons for local customization as needed. The application is used by $13 \mathrm{DOE}$ complex sites as of 2011. LANMAS serves many DOE complex sites and has eliminated the need for duplicative and redundant systems development. It is currently under evaluation for seven more sites. (6)

LANMAS has an active user community that host training seminars and user group meetings annually across the county. Instructor-led classes are held frequently at DOE complex sites using a mobile training classroom.

\section{OPPORTUNITIES FOR THE FUTURE}

Collaboration benefits have already been identified and recognized through a number of joint meetings and structured collaboration sessions such as one held at Savannah River in November 2010. Several sites, including contractors and DOE, came together and presented solutions, experiences, and best practices on topics such as wireless, RFID, single sign-on technologies, GIS, green IT, and accountability systems using RFID. There were also detailed technology discussions and forums held on video conferencing, VoIP telephony solutions, and business collaboration tools.

Collaboration can move from current point solutions to integrated solutions for DOE complex sites, reducing the cost to deliver a solution, and increasing the likelihood of success of a new or unfamiliar technology. Working together on a larger scale has the potential to influence products through coordinated procurement strategies and buying power to meet specific DOE business or cyber security needs.

Next steps for increasing collaboration and CoE usage include:

- Continuing planned, interactive meetings, with clearly defined objectives using face-to-face meetings and working sessions on best practices and adaptation actions, clearing houses, and joint or shared pilots 
- Determine and evaluate CoEs based on clusters of technological expertise; Promote increased use of $\mathrm{CoE}$ to accelerate deployment of technologies in a rapid and cost effective manner throughout DOE complex sites

- Evaluate IT delivery opportunities for collaboration between sites (i.e. Data Center consolidation, cloud computing) when management and operating (M\&O) contracts are renewed with DOE

\section{REFERENCES}

(1) CRAIG, W., FISHER, M., GARCIA, S., KAYLOR, C., PORTER, J. \& REED, L. Generalized Criteria and Evaluation Method for Center of Excellence: A Preliminary Report. 7. CMU/SEI-2009-TN-011. Software Engineering Institute, Carnegie Mellon University. (December 2009).

(2) (http://www.energy.gov/organization/index.htm)

(3) NELSON, R. State of IT 2010 Presentation, American Recovery and Reinvestment Act (ARRA) PowerPoint Presentation. CH2M Hill Plateau Remediation Company (2010)

(4) COMBS, C. ARRA wireless/Wimax cost savings documentation, including 182B Site utilities building, and Hanford Barcode facility projects. (2010)

(5) SCHEVE, D. Sustainability in On-Site Shipping. Bechtel Jacobs Company. 2010.

(6) Savannah River M\&O Contract, DE-AC09-085R22470 